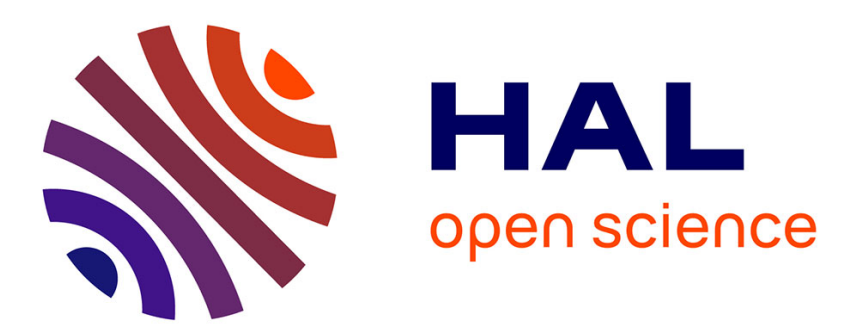

\title{
Integrated System for students' Evaluation Using KM Approach
}

Rabih Haddad, Eunika Mercier-Laurent

\section{To cite this version:}

Rabih Haddad, Eunika Mercier-Laurent. Integrated System for students' Evaluation Using KM Approach. IFIP International Workshop on Artificial Intelligence for Knowledge Management (AI4KM), 2018, Stockholm, Sweden. pp.14-24, 10.1007/978-3-030-52903-1_2 . hal-02266328

\section{HAL Id: hal-02266328 \\ https://hal.science/hal-02266328}

Submitted on 13 Aug 2019

HAL is a multi-disciplinary open access archive for the deposit and dissemination of scientific research documents, whether they are published or not. The documents may come from teaching and research institutions in France or abroad, or from public or private research centers.
L'archive ouverte pluridisciplinaire HAL, est destinée au dépôt et à la diffusion de documents scientifiques de niveau recherche, publiés ou non, émanant des établissements d'enseignement et de recherche français ou étrangers, des laboratoires publics ou privés. 


\title{
Integrated System for students' Evaluation Using KM Approach
}

\author{
Rabih Haddad and Eunika Mercier-Laurent \\ University of Reims Champagne-Ardenne,CRESTIC Laboratory \\ EPITA Engineering School of Computer Science \\ http://www. univ-reims.eu/ \\ http://www.epita.fr/en
}

\begin{abstract}
With the number of international students increasing globally and the mobility of students is becoming a condition to secure a good job and to gain a shining career, evaluating candidates prerequisites is becoming challenging. This paper presents how knowledge management approach using AI techniques could help academic institutions in the evaluation of international students profiles by providing an adapted methodology. This methodology implemented in the proposed system will help institutions gain more time in processing students files, provide accurate evaluation of candidates by taking their cultural background into consideration and avoid human errors.
\end{abstract}

Keywords: Higher Education, International Students, Knowledge Management, Text Mining, and Speech Recognition,

\section{Introduction}

France hosts each year international students willing to pursue their higher education in different fields. Their presence compensates for the relative lack of talented French students. The state and the French educational organizations want to increase the number of students to improve the position of the French educational system vis-a-vis the Anglo-Saxon system, among others.

More than 300,000 students annually from 180 different countries got enrollment in the French Universities and Graduate Schools. These academic institutions receive thousands of applications of the students who have completed their high school, bachelor, or masters degrees. This diversity of students profiles and their different academic background make accurate assessment an extremely challenging task. Up to now, the prior learning assessment of candidates and the processing of their applications are done manually and hence these tasks are time consuming and involve a lot of human potential errors in the selection. In addition, the distinctiveness of the French education system especially with its "Grandes Ecoles" that are unique, complicates the task of evaluation. International standard exams like SAT, GMAT, GRE are insufficient to conduct a full assessment. 
What is missing? As per our knowledge existing systems lack of considering criteria such as cultural aspects, level of education in each country, motivation, real meaning of motivation letter, and emotional intelligence. In the light of the current state of the art and on our knowledge, there is no automated intelligent system that performs a multi-criterion evaluation of international students by multi-media and multi-modal interaction with them. Knowing the proposed programs, computer trends and needs of students, this system should also propose an adjustment of programs, according to the students level. Here comes the need for automated multi-criteria system for the evaluation of students knowledge and motivation.

Many researchers and universities have worked on several systems to evaluate the students profiles to provide coherent admission results and to process the maximum number of applications possible. One of these approaches is to compare the profiles of new applicants with those who have similar profiles and have already validated their academic programs. A second approach was based on ranking of applicants by using the available historical data and predictive analysis to detect the risk of admitting those candidates. Athors use these data to orient stduents toward a specifcied major or domain. In my opinion, all of these approaches do not serve to solve the main problem presented in this paper as they do not provide a subjective and adapted assessment exercises. Also, those systems do not evaluate international students attended universities and their learning outcomes. In addition, the decision support system implemented do not use the latest technology.

In this paper, we are going to present the related work, research methodology, challenge, and the proposed system for evaluating the stduents' profile using knowledge management.

\section{Challenge}

To remove this lock and define an effective system architecture, a deep understanding of the admission principles and related contexts is mandatory. Existing experience and explanation of the admission problem from the educative point of view must also be considered.

Today applying to any degree seeking program in France or anywhere in the world nationally or abroad requires that candidates should undergo an admission procedure to assess the profile of candidates and to announce the final decision (admission/refusal of candidates). Admission systems vary from one country to another and from one institution to another. The characteristics of each country and institution shape the admission system, however there is a big percentage of communality between these systems as they require the same traditional documentation, evaluation, information: admission and languages proficiency exams, interviews, CVs, transcripts, motivation letters, and recommendations letters. 


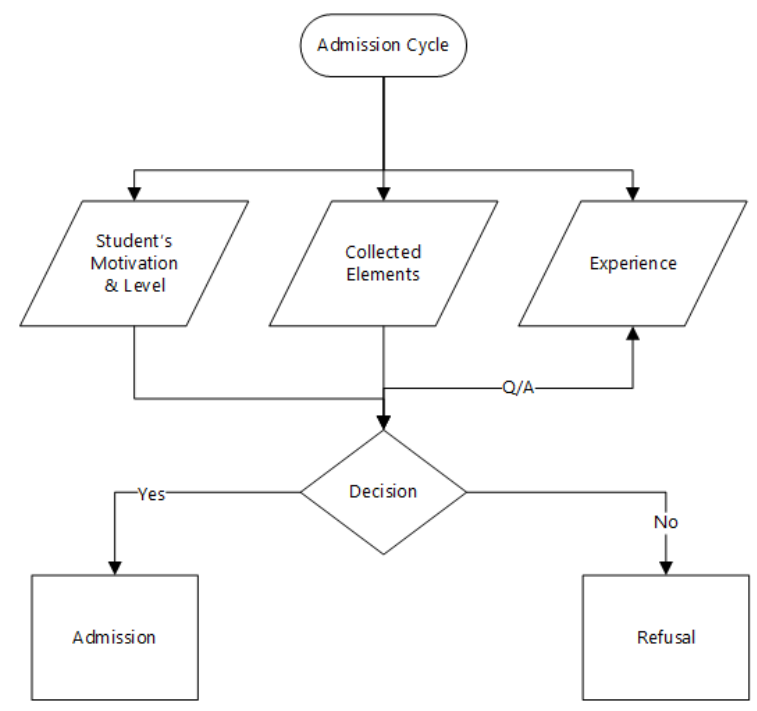

Fig. 1. Current Admission Cycle

\subsection{Admission Systems}

Up to now, all institutions need the candidate information and exams results to decide of the admission status of candidates. The admission procedure that is widely used worldwide and in France is described as follows:

- Students apply online on the institution website by supplying all the relevant and requested documents.

- Admission teams process the files following the order:

- Relevance of the candidate to the requested major

- Candidates high school or bachelor grades

- Candidates experience and skills

- Interview conduction (remote or face to face) to detect: genuineness, motivation, and capacity

- Exams conduction to detect knowledge and practice

- Financial status (mainly Anglo-Saxon institutions)

- Results announcements

\subsection{Knowledge Blocks}

As an entry point to understanding the admission system, we should look at 2 major knowledge blocks that contribute to the relevant evaluation of students profiles: the Curriculum Vitae (CV) and the online interview. The CV still is an important document that helps the admission committee identify important 
information about the candidates and provide knowledge on students academic and career path. The online interview helps the admission committee to detect motivation and validate the coherence and genuineness of the candidates vis-a-vis their CVs and profiles. For this purpose, the online interviews will be registered and rerun for the offline evaluation.

\section{Curriculum Vitae (CV)}

This block is very essential in the evaluation process. In the current systems the CV students are not taken into consideration as the evaluation logic only depends on the profiles of previous students who have succeeded a certain curriculum. Hence it depends on a comparative mechanism that might be valid for students coming from the same background but might fail for a diversified group of students. This block should provide the below information about each candidate:

- Basic: to detect the country of origin of each candidate, age and gender. The country will be a crucial factor in the adapted evaluation since a cultural impact matters here.

- Academic background: to detect the institution attended by the candidate and the highest degree obtained and the number of academic years after high school. This will help also to compile a list of academic institutions worldwide that will be ranked based on students success after enrollment and pursuing of classes.

- Professional experience: to verify the experience and skills acquired during this experience and its relevancy to the degree obtained. This will help also to compile a list of companies worldwide that will be ranked based on students success after enrollment and pursuing of classes.

Beside the direct knowledge that will be extracted from CVs, text mining procedures will be applied to derive knowledge from the unstructured text by merging all the above listed information. We will apply statistics, analytics, semantic and natural language processing algorithm and output of this exercise could be a weighted mark that aggregate CV main parts.

\section{Online Interview}

This exercise will serve in providing several types of knowledge on candidates. The online interview will be used to evaluate the English language level of candidates, their motivation, their capability to present themselves and present a coherent project of life, and some easy behavior aspects. The following 4 groups of knowledge could be extracted and evaluated from pre-registered video interviews:

- Detect the candidates oral ability by evaluating the first couple of minutes of their interview. 
- Analyze the candidates behavior in the video in terms of self-confidence and coherence.

- Evaluate the candidates answers to the interview questions to detect their motivation and relevance.

The idea is to retrieve the audio files from the registered interviews. The following techniques could be used to have a precise evaluation: speech recognition, Large Vocabulary Continuous Speech Recognizers, Speech analytics and Semantic Interpretation for Speech Recognition. The output of this simulator could be a weighted mark on a scale of 5 (poor, fair, good, very good, excellent for example). This mark could be an aggregate of the language, motivation, behavior, and character. There is a possibility also to convert to text to apply the text mining techniques.

\section{Proposed System}

The comprehension of the nature and contexts of the elements leading to the correct evaluation will guide the choice of knowledge models and processing methods. The proposed architecture will contain several communicating building blocks. Working on the algorithm requires treating a list of modules that build up the main architecture.

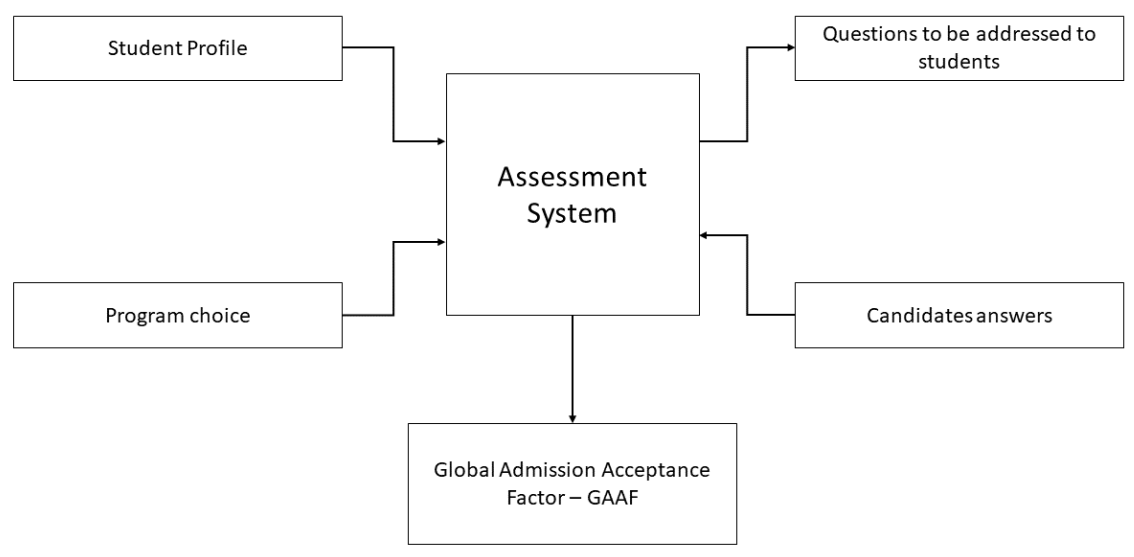

Fig. 2. System Principles

These modules can be in the below order: 
- Exploration of the elements gathered during collection phase and comprehension of the relations in systems components. Collected elements include information found during the educational research part. Exploration should include knowledge discovery and required analysis, as well as behavioral detection. The architecture will be adapted based on the educational research results.

- Generation of an adequate exam. The exam should consider the results found in the previous research and the academic profile of each candidate.

- Generation of the GAAF (Global Admission Acceptance Factor). This is the specific measure of student knowledge and capacity, that may vary according to the requirements.

\section{Conclusion}

In this paper, the integrated system of students evaluation using knowledge management approach is presented. The main aim is to assess how KM can help in a such system. By presenting and analyzing the 2 major knowledge blocks that constitute the evaluation system, we will be able to obtain an architecture that leads to an adapted evaluation of candidates. Also, this analysis will help us to validate the proposed solution using real cases and integrated feedback experience. The advantage of the proposed exam is that it does not assess only the aptitude and the knowledge of the candidate in a certain domain. It goes beyond the instantaneous evaluation of students to assess the experience, the skills acquired and the behavior in a multinational environment. The next step will be building up 2 simulators based on the $\mathrm{CV}$ text mining block and the interview evaluation block. These 2 simulators will be tested on hundreds of students applications we own to verify their outputs and validate the proposed algorithm. These 2 simulators will be crucial to building up the architecture of the proposed system and test in real case scenarios.

\section{$5 \quad$ References}

1. Simon Fong \& Robert P. Biuk-Aghai An Automated University Admission Recommender System for Secondary School Students ICITA 2009

2. Heba. M. Rashad \& Walid Mohamed Aly \& Osama Fathy Hegazy. An Educational Data Mining System for Advising Higher Education Students World Academy of Science, Engineering and Technology 2013

3. Khalid A. Fakeeh Decision Support Systems (DSS) in Higher Education System International Journal of Applied Information Systems (IJAIS) 2015

4. Rajan Vohra \& Nripendra Narayan Das Intelligent Decision Support Systems For Admission Management In Higher Education Institutes IJAIS 2011 
5. Nguyen, Haddawy P. A Decision Support System for Evaluating International Student Applications, Frontiers In Education Conference - Global Engineering: Knowledge Without Borders, Opportunities Without Passports, 2007

6. Moedas C. Open Innovation, Open Science, Open to the World, European Commission, June 2015

7. http://www.diplomatie.gouv.fr/fr/photos-videos-publicationsinfographies/ publications/enjeuxplanetaires-cooperation-internationale/documents-destrategie- sectorielle/article/laccueil-en-france-des-etudiants

8. M. Cerisier ben Guiga, Blanc J. Rapport dinformation 446 du Senat, 30 juin, 2005

9. C. Szymankiewicz : Conditions dinscription et daccueil des tudiants trangers dans les universits, Rapport MESR 2005-023

10. K.S. Thaung : Advanced Information Technology in Education, Advances in Intelligent and Soft Computing, 126, Springer, 2012

11. Machine Learning in Python: Essential Techniques for Predictive Analysis, Michael Bowles, 31 mars 2015

12. Data Analytics: Models and Algorithms for Intelligent Data Analysis, Thomas A. Runkler, 3 aot 2016 